Article

\title{
Beyond Socially Responsible Investing: Effects of Mission-Driven Portfolio Selection
}

\author{
Tizian M. Fritz and Georg von Schnurbein * \\ Center for Philanthropy Studies (CEPS), University of Basel; CH-4051 Basel, Switzerland; Tizian.Fritz@unibas.ch \\ * Correspondence: Georg.vonSchnurbein@unibas.ch; Tel.: +41-61-207-2392
}

Received: 28 September 2019; Accepted: 21 November 2019; Published: 1 December 2019

check for updates

\begin{abstract}
In their pursuit of value creation, charitable foundations are mission- rather than profit-driven. Therefore, foundations are also mission-driven investors. We explore the effects of mission-driven portfolio selection based on three model foundations, representing common fields of activity in Switzerland. Employing a moving block bootstrap approach, we simulate time series. Based on these model foundations and under the integration of qualitative company rating data, such as environmental, social, and governance-related characteristics (ESG), we find both negative and no significant financial effects of portfolio screening. However, screening portfolios substantially increases mission-driven portfolio quality. Additionally, screening reduces reputational risks and even leptokurtic return characteristics under special consideration of governance issues. After a joint analysis of financial and qualitative factors for portfolios with equity shares of $25 \%$ and $50 \%$, we did find strong enough evidence to encourage foundations to implement negative and positive screening criteria. Additionally, we argue that without the integration of mission-based qualitative criteria, for instance, the involvement in business activities contradicting the foundation's mission, an adequate evaluation of investment opportunities' desirability is not feasible.
\end{abstract}

Keywords: ESG; mission investing; nonprofit organizations; portfolio selection; charitable foundations; screening

\section{Introduction}

The number of foundations has rapidly increased within the past decades and today foundations have significant amounts of assets to invest. In the US, for instance, the total assets of foundations in 2015 summed up to $\$ 890$ billion, in Switzerland a total of $\$ 97.4$ billion for 2016 is reported, and the 300 largest foundations in the UK combined $\$ 79$ billion in 2017. As other types of nonprofit organizations (NPOs), too, foundations are utility—rather than profit-maximizing organizations [1]. Therefore, they are characterized as being "mission-driven" [2], as their utility is derived from the degree of mission achievement. Traditionally, foundations fulfill their mission using the returns of their capital. The capital, however, is invested without any regard to mission or social purpose. This may cause counterproductive results as specific investments might derogate from the social purpose pursued with the returns. Hence, if foundations align their investment decisions with their mission, they must not use their funds for supplying risk capital to companies that show major and structural involvement into controversies related to the mission [3]. One can hardly imagine that foundations would fund beneficiaries involved in activities with widespread negative environmental impact due to hazardous emissions or human rights abuse and child labor. Earning returns through the investment in companies involved in such activities may meet the same standards. Thus, a mission-driven portfolio selection goes beyond usual socially responsible investing (SRI)-selection, as the purpose of a foundation may be much more focused. For example, for a foundation in health services investing in green consumer products is not necessarily mission-driven. Revelli and Viviani conclude that research 
should analyze "the real extra-financial performance of SRI in relation to its level of ethicality" [4] (p. 171). Answering this call, we focus on the specific case of charitable foundations as investors with high moral obligations, in order to analyze financial and qualitative factors for portfolio selection.

As research question we formulate: How does a mission-driven portfolio selection affect investment outcomes? Specifically, we analyze what effects mission-driven portfolio selection has on performance, risk, disbursements, and level of mission achievement. The analysis is based on three generic models of foundations that operate in some of the most common fields of activity: Social and health services (SHS), arts and culture (AC), and animal and environmental protection (AEP).

In contrast to existing research on the financial performance of SRI, our analysis puts the foundation's mission at the center of evaluating performance and risks. We understand the linkage of grant making and investment policies as a mission-driven form of asset-liability management (generally referred to as "mission investing", MI, see [5]): The organization's mission acts as its central liability in terms of an obligation to the (potential) beneficiaries. Hence, portfolio selection is based on factors material to the investing organization in terms of direct influence on organizational performance. This means that even under potential lower financial performance foundations may still find a portfolio screened for its mission-related values more desirable, as it either offers possibilities of realizing synergies or at least eliminates conflicts of aim.

In this study, we conducted a comparison of screened and unscreened equal-weighted portfolios. Screening involved the exclusion of business activities that may be deemed problematic (such as animal testing or weapon manufacturing), specific minimum ratings for the areas of environment, society, and governance (ESG factors), or the exclusion of companies involved in controversies (such as human or labor rights violations). In contrast to previous studies, we did not use KLD data, which consists only of dummy variables, but incorporated further qualitative factors. Our analysis is based on historic market data and ESG company ratings as well as information on controversies and business involvement of 500 companies listed in the MSCI World Index between 2007 and 2015. We generated new financial time series applying a moving block bootstrap approach to historic data to achieve robust results. The screening criteria are based on three generic mission statements derived from an extensive text analysis of Swiss foundations' mission statements. Per construction, all screened portfolios display significantly higher portions of A- to AAA-rated companies with regard to their ESG performance. Further, by positively screening portfolios and focusing on topics material for the foundations' individual mission, our analysis yielded that governance-related factors have very positive qualitative effects, while not negatively affecting return characteristics and even reducing kurtosis of returns. The focus on social and environmental factors leads to significant higher ESG company ratings, while negatively affecting return characteristics. However, annual disbursements do not show statistically significant differences from unscreened portfolios in the period considered.

The remainder of this article is structured as follows: In an initial literature review, we analyze how foundations differ in the way of making and evaluating investment decisions and how these differences may be addressed by value-driven investment concepts. In this analysis, we also highlight empirical findings related to value-driven concepts such as SRI and how these findings affect our analysis. Building on this review, we introduce our methodology. Simulations building on historic market and rating data from MSCI ESG Research are used to evaluate our three model portfolios. Finally, we present our results and formulate implications for both researchers and practitioners.

\section{Literature Review}

Research on the combination of financial and qualitative factors in mission investing (MI) is scarce $[6,7]$. However, there exists a great amount of research devoted to socially responsible investment (SRI), a concept closely related to MI. Before we further elaborate on the concepts of MI and SRI, it is important to understand the specific nature of foundations. As any other nonprofit organization, a foundation is bound to the nondistribution constraint as introduced by Hansmann [8]: Making profits is an instrument for mission achievement. The classic idea of a foundation is that the returns from the 
endowment are used to promote a social purpose [4]. Formerly, the aim was to generate high returns in order to provide high budgets for donations. Today, asset allocation and grant distribution are not seen delinked anymore. In contrast, entering the market economy creates mission-market tensions [9].

In order to overcome these tensions, scholars such as Emerson [10] promote the idea of MI, i.e., the merging of investment and programming policies. Following this approach means that the investment, at least, should not harm the social purpose of the foundation. In a positive sense, the investment has a common link to the social purpose. In that sense, an investment cannot be solely socially responsible, but it has to affirm the social purpose of the foundation. This is motivated by (1) preventing conflicts of aim and (2) the realization of potential synergies [11]. Wood and Hagerman [5] further mention that the realization of leverage effects are seen as the main motivation and conclude that more research on MI is needed. Derived from the basic instruments of SRI, MI can be implemented using three instruments: Screening, shareholder advocacy, and proactive mission investing [12,13]. Currently, the instrument of screening (the explicit exclusion or inclusion of companies or industries) is most often used [7]. We, therefore, focus our analysis on the effects of applying investment screens to portfolio selection.

Screening is an established technique in the field of SRI, but there is criticism with regard to a mismatch of its intentions and effects. De Colle and York [14] put forth that through the simple exclusion of single companies no positive effects are achieved. They conclude that through the application of negative screening, SRI becomes rather an individually responsible than a socially responsible way of investing. However, in the case of foundations with a given mission statement, this may exactly be the purpose, i.e., having an investment strategy that reflects individual values.

Empirically, the discussion of screening mechanisms based on social and personal values has mainly been performed in the context of SRI (and corresponding funds). In an early study, Ferris and Rykaczewski [15] emphasize the risk of SRI investments for pension funds. Hamilton, Jo, and Statman [16] formulate three hypotheses on how screening mechanisms may influence expected returns com-pared to conventional portfolios: (1) There is no influence as SRI features are not priced, (2) SRI funds display lower expected returns as the cost of capital $(\mathrm{CoC})$ is lowered through appreciation of company value, or (3) SRI funds display higher expected returns, as the probability of negative information is underestimated by the majority of market participants. They then find that the market does not price social responsibility characteristics. In further articles covering the topic, Kempf and Osthoff [17] find high abnormal returns for portfolios going long in companies with high ratings and going short in companies with low ratings. Bello [18] finds no significant differences between SRI and regular mutual funds, including performance and diversification. Statman [19] concludes that SRI indices display higher social scores than the S\&P 500 and simultaneously generally exceed the index in terms of return. Nofsinger and Varma [20] find that SRI funds outperform in times of market crisis and underperform in times of bull markets. Instead of a linear relationship, Barnett and Salomon [21] show a curvilinear relationship between screening intensity and financial return. The initial exclusion of stocks due to few screens applied lowers performance, while the application of further screens again increases performance. In a more recent article, the same authors also find a curvilinear relationship between KLD (a company supplying SRI screens, now part of MSCI Inc.) scores and financial performance, which suggests that "it is more financially beneficial to be maximally socially responsible than minimally socially responsible" [22], (p. 1315).

Except for Schröder [11], there exists no published research dedicated to the simulation of portfolio performances of foundations taking value-driven selection criteria into account. Using vector error correction models for simulation, he applies general SRI criteria for the selection of indices. Under consideration of payout rules, Schröder [11] concludes that there is no empirical evidence that would lead to a discouragement of investing in such funds. While these findings are important with regard to the discussion of fiduciary duties, they do not incorporate the peculiarities of foundations' missions and fields of activity. The following data analysis offers an innovative combination of quantitative and qualitative data, addressing the investment decisions of mission-driven investors going beyond SRI investments. 


\section{Materials and Methods}

Our study was a mixed methods approach combining moving block bootstrap, text mining, and utility-based evaluation. By this, we connected quantitative financial market data with qualitative information about foundation purposes and their restrictions for investments. Following insights from the previous literature review, the data analysis tested effects in performance and disbursement of mission-driven, screened portfolios compared to unscreened portfolios, as well as effects on the degree of diversification and average levels of ESG ratings. This analysis was based on an evaluation model introduced by [7] which we expanded for the specific aim of this article. The following subsections will give a brief overview of the methods used for simulating market and rating data and thematic portfolios construction, as well as the basis of our study's evaluation model.

\subsection{Moving Block Bootstrap}

We used a nonparametric approach of simulating market data, as the objective of our article was not the identification of pricing factors. Additional to historic time series, we also included historic rating data relating to qualitative factors of companies, such as the involvement in certain industries possibly deemed problematic and ratings with regard to their environmental, social, and governance-related performance (ESG factors). Employing a moving block bootstrap (MBB) approach, we simulated time series $[23,24]$ and subsequently analyzed differences in screened and unscreened portfolios. This method is not very often applied to financial time series, given that it is "common to impose some kind of model structure" [25] (p. 986). However, this did not pose a limitation to our exploratory approach, but rather enabled us to use an efficient way of simulating financial time series [26]. In using the MBB approach, there was no need to mimic complicated structures and non-normal distribution characteristics of financial market data (for stylized facts, see Cont, [27]). This also evaded the inherent risk of possible false assumptions regarding market and pricing model misspecifications.

MBB generates financial time series by resampling with replacement from existing data. This resampling method differs from other block bootstrapping approaches as blocks are chosen randomly within the original data and that these blocks may overlap. Still, the block length of consecutive values is fixed. Thus, determining the optimal block size is central to preserving time dependence present in the initial data. To account for this, we employed the method proposed by Patton, Politis, and White [28] for choosing an optimal block length. We directly implement the function "b.star" supplied by the package "np" for R statistical software (https://cran.r-project.org/web/packages/np/index.html) in our simulation, which applies the method suggested by Patton et al. [28]. We simulated 10,000 new sets from the existing data to guarantee robust results.

\subsection{Thematic Portfolio Construction}

Our analysis is based on three theme-specific mission statements of foundations, derived from a text mining analysis of the mission statements of 6368 Swiss foundations. Foundations in Switzerland are set up under civil law as an endowment, which has been dedicated to a specific, charitable purpose. A foundation is governed by a board, but has neither members nor owners, as the endowment constitutes an institution, which belongs to itself [29]. We analyzed the existing statements statistically and then rephrased them into several new statements, which represent the most common fields of activity following the classification of National Taxonomy of Exempt Entities (NTEE). We based our rephrasing on the most frequent words present in mission statements in each field of activity. To qualify as "most common" the key word stems had to appear on average in at least $15 \%$ of all cases. A higher percentage would have limited the number of words too much for the small subgroups. Table 1 presents the separation of fields of activity with the respective frequency and includes the theme-specific mission statements of the three areas relevant for this survey.

We implemented this process using another package available in R statistical software called " $\mathrm{tm}$ " (https://cran.r-project.org/web/packages/tm/index.html). The analysis involved the removal of stop 
words (like "and", "the", etc.) as well as stemming of words (i.e., the retrieval of word radicals through erasing word suffixes; for an overview of these techniques see Feinerer, Hornik, and Meyer [30]).

Table 1. Areas of activity of Swiss foundations with theme-specific mission statement $(n=6368)$.

\begin{tabular}{|c|c|c|c|}
\hline Group & Overall Area of Activity & NTEE-CC Subgroups & $\%$ \\
\hline 1 & Social \& health services & L20, P30, P50, P70, P80, P99 & 21.94 \\
\hline $\begin{array}{c}\text { Generated mission } \\
\text { statement }\end{array}$ & \multicolumn{3}{|c|}{$\begin{array}{l}\text { The foundation supports aged, elderly, disabled, needy, and families that have gotten into } \\
\text { difficulties. It may do so through supplying financial support, offering affordable housing } \\
\text { as well as assisted living, and may itself operate such an institution (e.g., nursing home). }\end{array}$} \\
\hline 2 & Arts \& culture & A20, A40, A60, A90, A99 & 10.98 \\
\hline $\begin{array}{c}\text { Generated mission } \\
\text { statement }\end{array}$ & \multicolumn{3}{|c|}{$\begin{array}{l}\text { The foundation promotes artistic and cultural activities. It may do so through supplying } \\
\text { financial support to artists, granting scholarships, awarding prizes, supporting exhibitions } \\
\text { and events, acquiring works and making them publicly accessible. }\end{array}$} \\
\hline 3 & Museum \& history & A50, A80 & 9.16 \\
\hline 4 & Education \& training & B20, B30, B80 & 7.40 \\
\hline 5 & Research \& universities & A70, H90, V20 & 4.95 \\
\hline 6 & International development & Q30 & 4.40 \\
\hline 7 & $\begin{array}{l}\text { Animal \& environmental } \\
\text { protection }\end{array}$ & $\mathrm{C} 30, \mathrm{D} 20$ & 3.16 \\
\hline $\begin{array}{c}\text { Generated mission } \\
\text { statement }\end{array}$ & \multicolumn{3}{|c|}{$\begin{array}{l}\text { The foundation has the objective of environmental and animal protection in Switzerland } \\
\text { and abroad. It especially supports organizations financially which carry out projects and } \\
\text { take measures in the area of sustainable landscape protection and preservation of } \\
\text { endangered biotopes and habitats. }\end{array}$} \\
\hline 8 & Christianity & $\mathrm{X} 20$ & 2.76 \\
\hline 9 & Sports & N60 & 1.13 \\
\hline \multirow[t]{2}{*}{10} & Business \& industry & S40 & 1.04 \\
\hline & Total & 25 subgroups & 66.90 \\
\hline
\end{tabular}

In a further step, both authors independently filled out a matrix with negative and positive screening factors with regard to the theme-specific mission statements. For the negative factors, we individually decided which business industries directly opposed the organization's mission. The positive screening factors were relevant for determining which minimum standards companies must meet in order to be selected for portfolio construction. The differences in the mapping process were resolved in a final joint discussion. A similar procedure is also used by Khan, Serafeim, and Yoon [31], who hand-map data on sustainability investments. In order to cover a diverse set of screening rules, we finally selected three theme-specific mission statements to be included in our quantitative analysis, which displayed major differences in said selection rules. The matrices relevant for stock selection for these three model foundations can be found in Table A1 in the Appendix A.

\subsection{Evaluation}

The evaluation of differences between screened and unscreened portfolios is split into financial and qualitative aspects. We based this differentiation on the assumption that foundations (as any other NPO) have a multi-attribute utility function. Derived from previous work [7], we subsequently present an expanded model capturing the organization's utility in a given period $\left(U_{t}\right)$ in Equation (1):

$$
U_{t}=p_{t} \delta+\frac{I_{t-1}+I_{t}}{2} \gamma_{t}
$$

First, the organization's utility stems from the impact created through its annual payouts $\left(p_{t}\right)$. We characterized this impact by weighting the amount of payouts by an impact factor $(\delta)$. This factor took positive values, which depend on the effectiveness of the organization's program policy. Second, through supplying risk capital to companies, the organization's investment may also have an influence 
on its (potential) beneficiaries. Therefore, the average of the annual portfolio's value $\left(\left(I_{t-1}+I_{t}\right) / 2\right)$ was also weighted with an impact factor $\left(\gamma_{t}\right)$, which is dependent on the portfolio's annual composition. We assumed that this factor was lower than $\delta$, and may display positive or negative values. It took negative values if the invested assets contradict the organization's mission.

Switzerland, as our main data source, does not have specific payout regulations [29]. However, it is customary for foundations to spend between $2 \%$ and $3 \%$ of invested assets annually on their mission and beneficiaries (based on estimations by von Schnurbein, [32]). Thus, we implemented a payout rule for Switzerland as follows: $p_{t}=I_{t} \cdot 0.025$.

Integrating the organization's utility function in Equation (1) into standard mean-variance optimization [33] directly yielded a complete model upon which the desirability of a chosen investment opportunity can be analyzed. However, the actual size of the impact factors $\gamma$ and $\delta$ were difficult to determine and highly dependent on the organization's individual characteristics, operations, and strategy. We therefore split the final evaluation into different parts, reflecting key indicators from the evaluation model in Equation (1) as well as mean-variance optimization. These included: Financial performance, disbursed funds, portfolio variance, and average ESG ratings (as a proxy for $\gamma$ ) including their confidence intervals. As we assumed the impact of disbursed funds to be independent from time and investment decisions, we compared payouts exclusively on a monetary basis. Additionally, to account for different levels of organizational risk tolerance, we simulated portfolios with different asset allocations between bonds and equity. The equity shares of the portfolios ranged from $25 \%$ to $100 \%$ in steps of $25 \%$ each.

\subsection{Market Data}

Market data for bonds and equities covered the time span of January 2007 to April 2015. This equaled the time period of available qualitative company ratings from MSCI ESG Research. For equity, we included the 500 biggest companies listed in the MSCI World Index for which all relevant historical rating data were available and were listed in the index at least since 2007. Company size was based on market value as of end of April 2015. We downloaded monthly total return data in United States dollar (USD) from Datastream and transformed said data to monthly log returns. Market data for monthly bond returns in USD were also downloaded from Datastream and stemmed from total return data from the Bank of America Merrill Lynch Global Broad Index. These were also transformed to monthly log returns. A descriptive summary statistic can be found in Table 2 below.

Table 2. Descriptive statistics of market data (monthly log returns).

\begin{tabular}{cccccc}
\hline Asset Class & Mean & Median & Min. & Max. & SD \\
\hline Bonds & 0.0034 & 0.0022 & -0.0397 & 0.0718 & 0.0167 \\
Equity & 0.0055 & 0.0088 & -0.2232 & 0.1572 & 0.0613 \\
\hline
\end{tabular}

Note. Data retrieved from Datastream. Equity statistics are based on an equally weighted portfolio of 500 stocks.

\subsection{MSCI ESG Research Data}

The selection of stocks as well as the evaluation of mission-driven impacts of the portfolio were based on the following data supplied by MSCI ESG Research: (1) Business involvement [34], (2) general ESG ratings [35], and (3) involvement in controversies [36]. Data on business involvement included dummy variables regarding revenue sources or ownership structures that may be deemed problematic (such as adult entertainment or landmines). Historical ratings were not available for these data. We therefore assumed that the exposure had not significantly changed over time. However, we removed companies from the involvement list that showed a current exposure to such businesses of less than $1 \%$ of annual revenue. General ESG ratings included letter ratings (AAA-CCC) for the overall performance of a company relative to industry peers and individual ratings for environmental, social, and governance performance in issues material for the respective industry (numeric equivalents to 
letter ratings, ranging from 10 to 0 ). These ratings were historically available on a monthly basis and are revised periodically by MSCI ESG Research. Data on the involvement in controversies represented information on an "ongoing situation in which company operations and/or products allegedly have a negative environmental, social, and/or governance impact" [36], (p. 6). The nature (structural or nonstructural) and severity of such controversies were rated on a scale of 0 (very severe and structural) to 10 (no controversy). These ratings were also historically available on a monthly basis and are revised periodically. Between 2007 and 2012 these ratings were only available on an aggregate basis. From 2013 onwards, the scores were divided into different subgroups.

\subsection{Final Selection Criteria}

The final selection criteria, as we present them in Table A1 in the Appendix A, were based on the theme-specific mission statements and further third party information and literature. We used this information to support our decisions whether a business activity should be included (1) or excluded (0) from the portfolio, if minimum ESG pillar ratings were relevant, or if companies should not have been involved in major controversies in certain areas.

For instance, we consulted the guidelines of the United States Conference of Catholic Bishops [37] to define whether adult entertainment, alcohol, contraceptives, and similar business activities and industries were an allowed investment for our model foundation active in the field of Christianity. Further, when compiling positive screening criteria with regard to overall industry-adjusted performance in the three ESG pillars, we followed the recommendations of the Swiss Foundation Code [38] which calls for a minimum degree of sustainability in investing assets. All foundations should, therefore, only invest in companies, which at least have a score of 4.3 (i.e., BBB or investment grade). As NPO usually receive tax exemption for pursuing a specific value-based mission (and, therefore, a form of risk premium, see Crimm, [39]), minimal efforts that guarantee no apparent conflicts of aim should be undertaken. Additionally, we assigned minimum requirements with regard to individual pillar ratings to certain foundations. For months where historic rating information was only available on the overall involvement in controversies, all companies had to display at least a score of 4 , which means no involvement in severe controversies.

For reason of clarity, we decided to concentrate the final analysis and simulation of portfolio development to three model foundations: Social and health services (SHS), arts and culture (AC), and animal and environmental protection (AEP). Results for the other seven model foundations can be directly obtained from the authors.

\section{Results}

Based on 10,000 replications and an initial endowment of 1 million USD, we subsequently present the financial and qualitative results of our analysis and will then proceed with the discussion.

\subsection{Financial Aspects}

Foundations derive utility from both the impact created through their payouts as well as the impact of their current investments. The analysis of the financial aspects thus includes the development of the invested assets as well as the funds which were dedicated as payouts to beneficiaries (see Table 3). Applying a Welch two sample $t$-test, we found that differences between screened and unscreened portfolios were statistically significant and negative for SHS foundations and AEP foundations on a $1 \%$ level. AC foundations did not show significant differences on the respective level. Although differences for $\mathrm{AC}$ foundations were statistically significant on a $5 \%$ level, the magnitude of the differences compared to the unscreened portfolios were rather low and ranged between $2.3 \%$ (equity share of $100 \%$ ) and $0.6 \%$ (equity share of $25 \%$ ). The average number of companies included in the screened portfolios were 142 (SHS), 289 (AC), and 135 (AEP). This was equal to an average exclusion rate of $42 \%(\mathrm{AC}), 72 \%(\mathrm{SHS})$, and $73 \%$ (AEP). 
Table 3. Statistics for portfolio values of screened and unscreened portfolios.

\begin{tabular}{|c|c|c|c|c|c|c|c|c|c|c|c|c|c|c|}
\hline \multirow[b]{2}{*}{ Group } & \multirow[b]{2}{*}{ Equity } & \multicolumn{4}{|c|}{$\begin{array}{l}\text { Welch Two Sample } t \text {-Test for Portfolio } \\
\text { Values of Screened and Unscreened } \\
\text { Portfolios (after } 100 \text { Periods, in } 1000 \text { USD) }\end{array}$} & \multicolumn{4}{|c|}{$\begin{array}{l}\text { Welch Two Sample } t \text {-Test for Pay-Outs of } \\
\text { Screened and Unscreened Portfolios (after } \\
100 \text { Periods, in } 1000 \text { USD) }\end{array}$} & \multicolumn{5}{|c|}{ Monthly Log Returns } \\
\hline & & Mean & $\begin{array}{l}\text { Lower } \\
95 \% \text { CI }\end{array}$ & $\begin{array}{l}\text { Upper } \\
95 \% \text { CI }\end{array}$ & $p$-Value & Mean & $\begin{array}{l}\text { Lower } \\
95 \% \text { CI }\end{array}$ & $\begin{array}{l}\text { Upper } \\
95 \% \text { CI }\end{array}$ & $p$-Value & Mean & Median & SD & Skew. & $\begin{array}{c}\text { Exc. } \\
\text { Kurtosis }\end{array}$ \\
\hline \multirow{4}{*}{ SHS } & $100 \%$ & 1559 & -200 & -138 & $<0.001 *$ & 262 & -19 & -13 & $<0.001 *$ & 0.0045 & 0.0070 & 0.0614 & -0.67 & 1.49 \\
\hline & $75 \%$ & 1392 & -132 & -91 & $<0.001 *$ & 246 & -13 & -9 & $<0.001 *$ & 0.0042 & 0.0068 & 0.0458 & -0.66 & 1.48 \\
\hline & $50 \%$ & 1274 & -79 & -55 & $<0.001 *$ & 234 & -8 & -5 & $<0.001 *$ & 0.0039 & 0.0071 & 0.0310 & -0.63 & 1.56 \\
\hline & $25 \%$ & 1197 & -38 & -24 & $<0.001 *$ & 226 & -4 & -2 & $<0.001 *$ & 0.0036 & 0.0066 & 0.0189 & -0.45 & 1.45 \\
\hline \multirow{4}{*}{$\mathrm{AC}$} & $100 \%$ & 1689 & -71 & -6 & 0.019 & 275 & -7 & 0 & 0.028 & 0.0052 & 0.0082 & 0.0617 & -0.78 & 1.92 \\
\hline & $75 \%$ & 1478 & -47 & -5 & 0.015 & 254 & -5 & 0 & 0.025 & 0.0048 & 0.0090 & 0.0461 & -0.77 & 1.89 \\
\hline & $50 \%$ & 1326 & -29 & -3 & 0.014 & 239 & -3 & 0 & 0.027 & 0.0043 & 0.0079 & 0.0312 & -0.73 & 1.90 \\
\hline & $25 \%$ & 1220 & -15 & 0 & 0.037 & 228 & -2 & 0 & 0.064 & 0.0038 & 0.0060 & 0.0190 & -0.51 & 1.58 \\
\hline \multirow{4}{*}{ AEP } & $100 \%$ & 1615 & -147 & -80 & $<0.001 *$ & 267 & -14 & -7 & $<0.001 *$ & 0.0045 & 0.0111 & 0.0656 & -0.71 & 1.54 \\
\hline & $75 \%$ & 1421 & -104 & -61 & $<0.001 *$ & 249 & -10 & -6 & $<0.001 *$ & 0.0042 & 0.0066 & 0.0491 & -0.70 & 1.55 \\
\hline & $50 \%$ & 1287 & -67 & -41 & $<0.001 *$ & 235 & -7 & -4 & $<0.001 *$ & 0.0039 & 0.0084 & 0.0333 & -0.67 & 1.63 \\
\hline & $25 \%$ & 1201 & -34 & -20 & $<0.001 *$ & 226 & -4 & -2 & $<0.001 *$ & 0.0037 & 0.0056 & 0.0199 & -0.49 & 1.55 \\
\hline \multirow{4}{*}{$\begin{array}{c}\text { no } \\
\text { screen }\end{array}$} & $100 \%$ & 1728 & - & - & - & 278 & - & - & - & 0.0055 & 0.0088 & 0.0611 & -0.81 & 1.90 \\
\hline & $75 \%$ & 1504 & - & - & - & 257 & - & - & - & 0.0050 & 0.0099 & 0.0455 & -0.79 & 1.87 \\
\hline & $50 \%$ & 1341 & - & - & - & 241 & - & - & - & 0.0044 & 0.0084 & 0.0307 & -0.75 & 1.90 \\
\hline & $25 \%$ & 1228 & - & - & - & 229 & - & - & - & 0.0038 & 0.0065 & 0.0186 & -0.51 & 1.68 \\
\hline
\end{tabular}

Note. ${ }^{*}$ Value is less than 0.0005. Excess kurtosis is calculated as kurtosis minus 3. 
When looking at the sum of payouts over the same 100-month period, we found similar results as in the analysis of portfolio values. Total payouts for SHS and AEP foundations were all statistically significantly lower than of the unscreened portfolios (on a 1\% level). AC foundations again showed significant differences on a $5 \%$ percent level, but only for higher equity shares between $50 \%$ and $100 \%$. The magnitude of the differences ranged between $-1.4 \%$ and $-5.8 \%$ (SHS), $-0.3 \%$ and $-1.3 \%$ (AC), and $-1.2 \%$ and $-3.9 \%$ (AEP).

Additionally to the analysis of differences in portfolio development and sum of payouts, we also present descriptive statistics of the distribution of monthly log returns. We did not perform a standard Welch two sample $t$-test for these numbers, as we were especially interested in the influence of the different screening rules on the higher moments of return distributions. The majority of the screened portfolios displayed values for skewness closer to zero than the unscreened portfolios as well as lower excess kurtosis. Furthermore, the summary statistics in Table 3 also show that AEP foundations have higher monthly median portfolio log returns than the unscreened portfolio for an equity share of $100 \%$.

\subsection{Qualitative Aspects}

As mentioned before, foundation performance is ultimately measured by the level of mission achievement. Therefore, the qualitative evaluation of portfolios with respect to mission alignment is crucial. Next to the fact that the screened portfolios excluded companies with business activities deemed problematic or the involvement into controversies, we included ESG ratings into our analysis as a proxy for the mission-related quality of the portfolios. Additionally, the exclusion or specific inclusion of companies affected the distribution across different sectors and countries.

By construction, the average rating for the screened portfolio was higher than for an unscreened. The share of AAA-rated companies, however, were especially high for SHS foundations (33\% vs. 14\% for unscreened portfolios) but also twice as high for AEP foundations (28\%). Again by construction, none of the screened portfolios contained companies rated below investment grade, while in the unscreened portfolio more than a fourth of all companies were rated BB or lower (cumulative share: $28 \%$ ). All screened portfolios displayed significantly higher ESG ratings on a 1\% level. As SHS and AEP foundations specifically focus on one of the three ESG pillars each, the respective ratings were especially high. In Table 4 we give an overview of two sample $t$-tests for all three ESG pillar ratings. Ratings only relate to the equity portion of the portfolio, as we did not have any data available on ESG performance for bonds.

Table 4. Statistics of Welch two sample $t$-test of ESG ratings of screened and unscreened portfolios.

\begin{tabular}{ccccccc}
\hline Group & Rating & Mean & Lower 95\% CI & Upper 95\% CI & $p$-Value & \\
\hline \multirow{5}{*}{ SHS } & E & 6.43 & 0.66 & 0.66 & $<0.001$ & $*$ \\
& S & 7.02 & 1.62 & 1.63 & $<0.001$ & $*$ \\
& G & 6.60 & 0.65 & 0.65 & $<0.001$ & $*$ \\
AC & E & 6.28 & 0.51 & 0.52 & $<0.001$ & $*$ \\
& S & 6.01 & 0.62 & 0.62 & $<0.001$ & $*$ \\
& GEP & 6.55 & 0.60 & 0.60 & $<0.001$ & $*$ \\
& E & 7.24 & 1.47 & 1.48 & $<0.001$ & $*$ \\
\multirow{5}{*}{ no screen } & S & 6.17 & 0.78 & 0.78 & $<0.001$ & $*$ \\
& G & 6.59 & 0.64 & 0.64 & $<0.001$ & $*$ \\
& E & 5.77 & - & - & - & - \\
\hline
\end{tabular}

Note. ${ }^{*}$ Value is less than 0.005 .

We based some of the screening factors on business involvements possibly deemed problematic. Thus, mission-driven screening may also influence the distribution of companies across different economic sectors. Table 5 gives an overview of average distribution according to the Global Industry Classification Standard (GICS). In this summary, we also included the degree of diversification (DD) 
across sectors according to a Hirshman Herfindahl Index (HHI), calculated as shown in Equation (2) below. $R_{i}$ denotes the percentage of an individual sector in the portfolio and $N$ the total number of industries. A value for $D D$ of 0 represents perfect concentration, a value of 1 perfect diversification.

$$
D D=\frac{1-\sum_{i=1}^{N} R_{i}^{2}}{1-\frac{1}{N}},
$$

DD is higher for two (SHS and AC) and lower for one group of foundations (AEP). Due to the exclusion of companies involved in animal factories and fur for AEP foundations, this decreased the percentage of healthcare (testing of cosmetic products) and consumer staples (dairies and livestock) sectors in the portfolio. As companies with better environmental ratings are preferred in this group as well, sectors such as financials, information technology (IT), and telecommunication services were overrepresented and energy and utilities underrepresented in the portfolio compared to an unscreened one. This specifically led to a slightly lower degree of sector diversification.

Table 5. Distribution among sectors of screened and unscreened portfolios (in percent) and degree of diversification (DD).

\begin{tabular}{cccccccccccc}
\hline Group & CD & CS & En. & Fin. & HC & Ind. & IT & Mat. & TS & Ut. & DD \\
\hline SHS & 14 & 6 & 4 & 24 & 9 & 9 & 13 & 5 & 8 & 7 & 0.97 \\
AC & 12 & 10 & 5 & 24 & 9 & 12 & 10 & 5 & 7 & 6 & 0.97 \\
AEP & 18 & 6 & 2 & 28 & 3 & 12 & 15 & 2 & 11 & 2 & 0.93 \\
no screen & 14 & 10 & 6 & 24 & 10 & 13 & 9 & 5 & 4 & 6 & 0.96 \\
\hline
\end{tabular}

Note. The following abbreviations denote the ten GICS sectors: CD, consumer discretionary; CS consumer staples; En., energy; Fin., financials; HC, healthcare; Ind., industrial; IT, information technology; Mat., materials; TS, telecommunication services; Ut., utilities.

\section{Discussion}

We assumed that charitable foundations have multi-attribute utility functions. The above-presented results, therefore, need to be jointly discussed to evaluate if mission-driven screening is actually utility enhancing or not, keeping in mind that the organization's mission will act as a central point of reference in evaluating risk and performance. We will subsequently do so for the three model foundations individually.

SHS foundations have a strong focus on social issues and also exclude business activities such as weapons, tobacco, or gambling. Additionally, like every screened portfolio in our sample, SHS foundations also commit to a minimum level of environmental and governance ratings. We observed significant financial loss for high equity shares in the portfolios compared to the unscreened ones. While these losses were still significantly different from zero for lower equity shares, the magnitude of these losses became relatively small, especially given the investment horizon of 100 months. While screening had negative financial impacts, the portfolio's qualitative aspects improved significantly. Average social company ratings were very high and foundations may report that they have not been supplying risk capital to companies involved in major labor rights controversies or earning money from weapon, landmines, and cluster bombs manufacturers. This guarantees an alignment to the social purpose and prevents reputational risks. The alignment and mission-related risk management involves a trade-off, which has to be balanced carefully. Given that the negative financial effects had low magnitudes for more realistic equity shares of $25 \%$ and $50 \%$, respectively, expected annual costs of such a trade-off were relatively low.

AC foundations have no specific focus on any of the three ESG pillars. However, our screening criteria tried to evade the involvement into human and labor rights controversies, which include freedom of expression and speech as well as equal treatment of men and women, two central values of international artists' associations. As part of the nonprofit sector, AC foundations still screen companies for a certain minimum degree of ESG ratings. We only found significant negative financial differences 
on a $5 \%$ level for screened portfolios, if any at all. The magnitude of these differences was low, indicating no real trade-off between financial and qualitative aspects. Although the average number of companies included in the portfolio was reduced by $42 \%$, we observe no negative effects regarding diversification. We, therefore, concluded that for $\mathrm{AC}$ foundations the screening rules introduced in this study did increase overall perceived utility. Given the dedication of the foundation's endowment to a specific purpose, the alignment of the invested assets with those values was feasible at low, if any, costs at all.

For portfolios of AEP foundations, we did apply rather strict and extensive screening rules. This primarily led to an average exclusion of $73 \%$ of all companies from the portfolio. This had significant financial as well as qualitative consequences. While average portfolio valuation as well as payout after a period of 100 months were significantly lower than those of an unscreened portfolio, magnitudes were lower than for SHS foundations. However, there was still an apparent trade-off between average returns and mission-specific qualitative aspects. Average environmental portfolio ratings were very high (AA) and the foundation may report to its beneficiaries, donors, and other stakeholders that it excludes companies involved in major environmental controversies as well as animal testing and factory farming, the production or trading of fur, as well as genetically modified organisms (GMO) and nuclear energy. Again, assuming realistic equity shares of $25 \%$ or $50 \%$, the financial loss of such screening rules had relatively low magnitudes with total payouts decreasing by $1.2 \%$ to $2.3 \%$ over a 100 -month period and portfolio valuation by $2.2 \%$ to $4.0 \%$, respectively.

Referring to the hypotheses by Hamilton, Jo, and Statman [16] on the effects of screened portfolios, our study led to mixed results for mission-driven investors. However, including qualitative information using ESG factors, mission-driven investors gained in terms of the overarching aim of mission achievement. Additionally, average ESG ratings of the screened portfolios were comparable to those of the top 100 sustainable funds available in Germany, Switzerland, and Austria [40], if not even higher. Especially with regard to social standards, all screened portfolios scored well above these sustainable funds (see Table 6 below).

Table 6. Comparison of average environmental, social, and governance-related (ESG) scores of screened portfolios and 100 sustainable funds available in Germany, Switzerland, and Austria.

\begin{tabular}{cccc}
\hline Group & E & S & G \\
\hline SHS & 6.4 & 7.0 & 6.6 \\
AC & 6.3 & 6.0 & 6.6 \\
AEP & 7.2 & 6.2 & 6.6 \\
sustainable funds & 6.5 & 4.9 & 6.2 \\
\hline
\end{tabular}

Note: The average score of the 100 sustainable funds as reported in [40] are also based on ESG rating data from MSCI, thus allowing a meaningful comparison.

Although foundations are not legally bound to actively screen their portfolios with regard to either negative or positive effects, our results suggest that foundations can increase their social mission fulfillment through investment selection without significantly risking their financial returns. Mission-driven portfolio selection may be an effective attempt to organize foundations as single entity in achieving social impact: Considering both the impact of grant making and the impact of capital investment as the holistic result in terms of mission fulfillment. In the following we highlight aspects of further research to develop a better understanding of this form of mission-driven investment.

\section{Limitations and Implications}

Given the exploratory nature of this study, we highlight several limitations. First, the main drivers behind differences in return characteristics cannot be identified in this study due to a lack of in-depth information. Additionally, the initial market dataset had an apparent survivorship bias, as companies were selected according to their market value in 2015 and were only included in the 
portfolio if they have already been listed in the MSCI World Index in 2007. However, as our analysis was based on the comparison of screened and unscreened portfolios of the same companies, this effect cancels out. In contrast to the analysis of Schröder [11], we worked with equal-weight portfolios and not buy-and-hold strategies. Although chosen for its simplicity, the "naïve" $1 / \mathrm{N}$ strategy does often outperform other strategies with regard to optimal diversification and performance (see, for instance, DeMiguel, Garlappi, and Uppal [41]). Combined with the necessity to constantly screen the portfolio for changing ratings, the applied strategy thus generated high turnover costs, which were not included in the above analysis. The results may, therefore, be limited from a cost perspective, which also includes the acquisition of rating information through data providers. Despite these limitations, we identified several interesting findings for future research and practical implications.

Our study added a more specific approach to the literature of responsible investing going beyond SRI. As the market for SRI investment grows, more specific restrictions will become inevitable. Our study is a first attempt to analyze the consequences of more selective investment strategies that are stemming from the legally binding purpose of foundations. Screening does not necessarily have significant negative impacts on portfolio evaluation and sum of payouts, as our simulations have shown. Although we found significant negative financial impacts for certain model foundations and equity shares, the positive qualitative improvements of the portfolio need to be considered unconditionally. These may outweigh the financial loss through improved organizational effectiveness and lower reputational risks [41]. The trade-offs, however, have to be carefully managed. We present ideas for such theoretical models in our analysis. A first line of further research is on cost effects. By using moving block bootstrap method on real market data, our study did not include pricing mechanisms. Further research should be conducted with an emphasis on how mission-driven selection criteria affect the return characteristics of the different portfolios. Analyses with regard to spanning effects, variance decomposition, and size- or sector-specific effects would complement our findings and add to a better understanding of what mission-driven investors have to expect from such value-based selection procedures. Additionally, a more in-depth analysis of the use of ESG factors in portfolio selection is necessary. Especially, interdependencies of the three pillars should be analyzed. Major data providers currently offer an extensive set of additional metrics such as $\mathrm{CO} 2$ emissions, energy efficiency, water usage, and the provision of access to healthcare, finance, and communications. These allow for an even more mission-specific screening of investment options and effective allocation of tax-exempt funds, not only with regard to their financial return characteristics, but also value-based factors. Finally, foundations as mission-driven investors might also make use of other instruments. To gain a more holistic view, research on the effects of shareholder advocacy, as well as proactive forms of mission investing (such as venture philanthropy and impact investing) is necessary. Public data on such forms of engagement, however, are extremely limited. Disaggregated data from foundations would be a promising starting point to analyze $\mathrm{MI}$ in its broader sense. Finally, a better understanding of impact measurement in foundations is needed. So far, there is a lack of coherent methods and indicators that would facilitate a joint impact analysis of grant making and investments [42]. Just as the ESG factors in the financial markets, such a set of indicators might strengthen the use of impact measurement among foundations.

Foundation managers and other mission-driven investors will profit from our analysis, as it enables them to better manage expectations with regard to future investment decisions. Our empirical analysis of the effects of mission-driven portfolio selection highlights two major implications: First, any given mission statement can be translated into investment policies using ESG factors and other portfolio screening methods. Second, even if mission-driven portfolio selection may lead to lower financial returns, it creates the necessary basis to report the impacts of a foundation's investment on its specific mission achievement. Thus, foundation managers should aim beyond standard SRI funds in order to increase the impact of the foundation's assets. The implementation of mission-driven investment strategies is essential, as the inclusion of value-based factors is not a matter of taste, but 
ultimately the assumption of the responsibility of foundations toward society, thus legitimating their unique role and privileges.

Author Contributions: Conceptualization, T.M.F. and G.v.S.; methodology, T.M.F.; validation, T.M.F. and G.v.S.; formal analysis, T.M.F.; resources, T.M.F. and G.v.S.; data curation, T.M.F.; writing-original draft preparation, T.M.F.; writing—review and editing, G.v.S.; visualization, T.M.F.; supervision, G.v.S.

Funding: This research received no external funding.

Acknowledgments: We give special thanks to Irene Reynolds Schier for her support in providing data on foundation purposes.

Conflicts of Interest: The authors declare no conflict of interest.

\section{Appendix A}

Table A1. Negative and positive screening criteria.

\begin{tabular}{|c|c|c|c|}
\hline \multirow[t]{2}{*}{ Criteria } & \multicolumn{3}{|c|}{ Group (See Table 1) } \\
\hline & SHS & $\mathrm{AC}$ & AEP \\
\hline Abortion $^{a}$ & 1 & 1 & 1 \\
\hline Adult entertainment ${ }^{a}$ & 0 & 1 & 1 \\
\hline Alcohol $^{\mathrm{a}}$ & 0 & 1 & 1 \\
\hline Animal welfare ${ }^{a}$ & 1 & 1 & 0 \\
\hline Contraception ${ }^{a}$ & 1 & 1 & 1 \\
\hline Fur $^{\mathrm{a}}$ & 1 & 1 & 0 \\
\hline Gambling ${ }^{a}$ & 0 & 1 & 1 \\
\hline $\mathrm{GMO}^{\mathrm{a}}$ & 1 & 1 & 0 \\
\hline Nuclear power ${ }^{a}$ & 1 & 1 & 0 \\
\hline Predatory lending a & 0 & 0 & 0 \\
\hline Fetal and stem cell a & 1 & 1 & 1 \\
\hline Tobacco $^{\text {a }}$ & 0 & 1 & 1 \\
\hline Cluster bombs ${ }^{a}$ & 0 & 1 & 0 \\
\hline Landmines ${ }^{\mathrm{a}}$ & 0 & 1 & 0 \\
\hline Firearms $^{\mathrm{a}}$ & 0 & 1 & 1 \\
\hline Weapon ${ }^{a}$ & 0 & 1 & 1 \\
\hline Minimum overall ESG score ${ }^{b}$ & BBB & BBB & BBB \\
\hline Minimum E pillar score ${ }^{b}$ & - & - & A \\
\hline Minimum $S$ pillar score ${ }^{b}$ & $\mathrm{~A}$ & - & - \\
\hline Minimum $G$ pillar score ${ }^{b}$ & - & - & - \\
\hline Env. controversy score ${ }^{c}$ & 5 & 0 & 5 \\
\hline Cust. controversy score ${ }^{\mathrm{c}}$ & 0 & 0 & 0 \\
\hline Human rights controversy score ${ }^{c}$ & 0 & 5 & 0 \\
\hline Labor rights controversy score ${ }^{c}$ & 5 & 5 & 0 \\
\hline Governance controversy score ${ }^{c}$ & 0 & 0 & 0 \\
\hline
\end{tabular}

Note. ${ }^{a}$ Based on MSCI Business Screening data (MSCI ESG Research, 2015a). ${ }^{b}$ Based on MSCI Intangible Value Assessment (IVA) ratings. BBB reflects an industry adjusted letter score equal to 4.3 points, A reflects an individual pillar score equal to 5.7 points (MSCI ESG Research, 2014). ${ }^{c}$ Based on MSCI Impact Monitor ratings, 5 points equal only moderate and nonstructural controversies (MSCI ESG Research, 2015b).

\section{References}

1. Valentinov, V. The Transaction Cost Theory of the Nonprofit Firm: Beyond Opportunism. Nonprofit Volunt. Sect. Q. 2008, 37, 5-18. [CrossRef]

2. Sawhill, J.C.; Williamson, D. Mission Impossible? Measuring Success in Nonprofit Organizations. Nonprofit Manag. Leadersh. 2001, 11,371-386. [CrossRef]

3. Stühlinger, S. In Need of Clarification: Current Perceptions of Impact Investing in the German and Swiss Foundation Sectors; Center for Philanthropy Studies: Basel, Switzerland, 2018.

4. Revelli, C.; Viviani, J.-L. Financial Performance of Socially Responsible Investing (SRI): What have we Learned? A Meta-Analysis. Bus. Ethics Eur. Rev. 2015, 24, 158-171. [CrossRef] 
5. Wood, D.; Hagerman, L. Mission investing and the philanthropic toolbox. Policy Soc. 2010, 29, $257-268$. [CrossRef]

6. Raymond, S. Changing Strategies for Philanthropic Giving: Implications for Financial Planners. J. Financ. Plan. 2010, 23, 44-49.

7. Fritz, T.M.; von Schnurbein, G. Nonprofit Organizations as Ideal Type of Socially Responsible and Impact Investors. J. Financ. Risk Persp. 2015, 4, 129-145.

8. Hansmann, H. The Role of Nonprofit Enterprise. Yale Law J. 1980, 89, 835-901. [CrossRef]

9. Sanders, M.L. Being Nonprofit-Like in a Market Economy: Understanding the Mission-Market Tension in Nonprofit Organizing. Nonprofit Volunt. Sect. Q. 2015, 44, 205-222. [CrossRef]

10. Emerson, J. Where Money Meets Mission: Breaking Down the Firewall between Foundation Investment and Programming. Stanf. Soc. Innov. Rev. 2003, 1, 37-47.

11. Schröder, M. Die Eignung Nachhaltiger Kapitalanlagen für die Vermögensverwaltung von Stiftungen; ZEW Wirtschaftsanalysen, Nomos: Baden-Baden, Germany, 2010; Volume 98.

12. Cooch, S.E.; Kramer, M.R. Compounding Impact: Mission Investing by U.S. Foundations; FSG Social Impact Advisors: Boston, MA, USA, 2007.

13. Viederman, S. Foundations and Mission-Related Investing. In The SRI Advantage: Why Socially Responsible Investing Has Outperformed Financially; New Society Publishers: Gabriola Islands, BC, Canada, 2002; pp. 205-212.

14. De Colle, S.; York, J.G. Why Wine is not Glue? The Unresolved Problem of Negative Screening in Socially Responsible Investing. J. Bus. Ethics 2009, 85, 83-95. [CrossRef]

15. Ferris, S.P.; Rykaczewski, K.P. Social Investing and Portfolio Management. Bus. Soc. 1996, 25, 1-7. [CrossRef]

16. Hamilton, S.; Jo, H.; Statman, M. doing Well while Doing Good? The Investment Performance of Socially Responsible Mutual Funds. Financ. Anal. J. 1993, 49, 62-66. [CrossRef]

17. Kempf, A.; Osthoff, P. The Effect of Socially Responsible Investing on Portfolio Performance. Eur. Financ. Manag. 2006, 13, 908-922. [CrossRef]

18. Bello, Z.Y. Socially Responsible Investing and Portfolio Diversification. J. Financ. Res. 2005, 28, 41-57. [CrossRef]

19. Statman, M. Socially Responsible Indexes-Composition, Performance and Tracking Error. J. Portf. Manag. 2006, 32, 100-109. [CrossRef]

20. Nofsinger, J.; Varma, A. Socially responsible funds and market crises. J. Bank. Financ. 2014, 48, 180-193. [CrossRef]

21. Barnett, M.L.; Salomon, R.M. Beyond Dichotomy: The Curvilinear Relationship Between Social Responsibility and Financial Performance. Strateg. Manag. J. 2006, 27, 1101-1122. [CrossRef]

22. Barnett, M.L.; Salomon, R.M. Does it pay to be really good? Addressing the shape of the relationship between social and financial performance. Strat. Manag. J. 2012, 33, 1304-1320. [CrossRef]

23. Künsch, H.R. The jackknife and the bootstrap for general stationary observations. Ann. Stat. 1989, 17, 1217-1241. [CrossRef]

24. Liu, R.Y.; Singh, K. Moving blocks jackknife and bootstrap capture weak dependence. In Exploring the Limits of Bootstrap; Wiley: New York, NY, USA, 2015; pp. 225-248.

25. Paparoditis, E.; Politis, D.N. Resampling and Subsampling for Financial Time Series. In Handbook of Financial Time Series; Springer: Berlin/Heidelberg, Germany, 2009; pp. 983-999.

26. DiCiccio, T.J.; Efron, B. Bootstrap Confidence Intervals. Stat. Sci. 1996, 11, 189-212.

27. Cont, R. Empirical properties of asset returns: Stylized facts and statistical issues. Quant. Financ. 2001, 1, 223-236. [CrossRef]

28. Patton, A.; Politis, D.N.; White, H. Correction to "Automatic Block-Length Selection for the Dependent Bootstrap" by D. Politis and H. White. Econom. Rev. 2009, 28, 372-375. [CrossRef]

29. Von Schnurbein, G.; Perez, M. Foundations in Switzerland: Between the American and the German Cases. Am. Behav. Sci. 2018, 62, 1919-1932. [CrossRef]

30. Feinerer, I.; Hornik, K.; Meyer, D. Text Mining Infrastructure in R. J. Stat. Softw. 2008, 25, 1-54. [CrossRef]

31. Khan, N.; Serafeim, G.; Yoon, A. Corporate Sustainability: First Evidence on Materiality; Harvard Business School: Boston, MA, USA, 2015; pp. 15-73.

32. Von Schnurbein, G. Der Schweizer Stiftungssektor im Überblick; Center for Philanthropy Studies: Basel, Switzerland, 2009. 
33. Sharpe, W.F. Expected Utility Asset Allocation. Financ. Anal. J. 2007, 63, 18-30. [CrossRef]

34. MSCI ESG Research. Business Involvement Screening Research-Definitions and Scope; MSCI ESG Research: New York, NY, USA, 2015.

35. MSCI ESG Research. Intangible Value Assessment (IVA) Methodology; MSCI ESG Research: New York, NY, USA, 2014.

36. MSCI ESG Research. ESG Impact Monitor Methodology; MSCI ESG Research: New York, NY, USA, 2015.

37. United States Conference of Catholic Bishops. Socially Responsible Investment Guidelines. Available online: http://www.usccb.org/about/financial-reporting/socially-responsible-investment-guidelines.cfm (accessed on 16 March 2019).

38. Sprecher, T.; Egger, P.; von Schnurbein, G. Swiss Foundation Code 2015; Helbing Lichtenhahn: Basel, Switzerland, 2015.

39. Crimm, N.J. An Explanation of the Federal Income Tax Exemption for Charitable Organizations: A Theory of Risk Compensation. Fla Law Rev. 1998, 50, 419-485.

40. Jochum, C.; Oehri, O.; Dreher, C. Top 100 ESG Aktienfonds Rating [Top 100 ESG Equity Fund Rating]; CSSP: Vaduz, Liechtenstein, 2015.

41. DeMiguel, V.; Garlappi, L.; Uppal, R. Optimal Versus Naïve Diversification: How Inefficient is the 1/N Portfolio Strategy? Rev. Financ. Stud. 2009, 22, 1915-1953. [CrossRef]

42. Von Schnurbein, G. Managing Impact and Recognising Success. In The Routledge Companion to Philanthropy; Routledge: London, UK, 2016; pp. 468-481.

(C) 2019 by the authors. Licensee MDPI, Basel, Switzerland. This article is an open access article distributed under the terms and conditions of the Creative Commons Attribution (CC BY) license (http://creativecommons.org/licenses/by/4.0/). 